CASE STUDY

\title{
A Faculty Member Learning with and from an Undergraduate Teaching Assistant: Critical Reflection in Higher Education
}

\author{
*Frank Daniello and Caroline Acquaviva, Lesley University, Massachusetts, USA
}

Contact: fdaniell@lesley.edu

\section{ABSTRACT}

This case study describes a student-faculty partnership between an undergraduate teacher education student and a faculty member of teacher education. This facultycentric partnership aimed to enhance the faculty member's critical reflection on his pedagogy in an introduction to teacher education course. In this jointly-written article, we offer student and faculty insights about the process we employed, the outcomes of our teaching and learning together, and the complexities of student-faculty working relationships stemming from power dynamics. We also provide recommendations for faculty and students looking to engage in collaborations. These recommendations center on defining partner roles, using video recordings, and addressing power dynamics between students and faculty within higher education. Drawing from our experience, we suggest that student-faculty partnerships are one fruitful avenue for improving the quality of instruction in higher education. They require minimum financial resources and can enhance faculty pedagogy, which will benefit current and future students.

\section{KEYWORDS}

students as partners, critical reflection, pedagogy, power dynamics, professional development

Quality of instruction in higher education strongly and directly impacts undergraduate learning (Commission on the Future of Undergraduate Education, 2017), yet despite the importance of high-quality teaching, limited attention is typically given to facilitating it. According to the Commission, "Faculty are rarely trained, selected, and assessed as teachers, and their effectiveness as instructors is rarely recognized or rewarded" (p. 12). When institutions do assess quality of instruction, it is primarily measured using student course evaluations. However, the validity and reliability of these evaluations have been widely criticized for a number of reasons, including low response rates (Goos \& Salomons, 2017; Spooren, Brockx, \& Mortelmans, 2013). While these findings are troubling, they are especially 
alarming within the context of teacher education. Teacher education programs must model best instructional practices, as teacher candidates look to our pedagogy to inform their future practice (Loughran, 2006). Therefore, teacher education faculty must employ high-quality instruction and continually assess their practice, a process that should exceed course evaluations, given the limitations of these instruments.

Despite the importance of improving teaching in teacher education programs, minimal information exists about their faculty's professional development (Swennen, Jones, \& Volman, 2010). For this reason, Phuong, Cole, and Zarestky (2018) recommend that teacher education faculty conduct rigorous self-study research about their own teaching. They go on to assert that "the better faculty understand their own learning, teaching and research process, the better they are able to impact students' learning and performance" (p. 384).

This case study centers on a faculty member examining his teaching practices and describes the student-faculty partnership the authors formed, as a faculty member of teacher education (Frank) and an undergraduate teacher education student (Caroline). Our partnership had a faculty-centric focus, and aimed to support Frank's critical reflection on his teaching practices in an introductory teacher education course. Our faculty-centric focus is different from most partnerships in that most are student-centric, focusing more on student outcomes than faculty outcomes. This suggests a "deficit mindset. . . which implies that engagement, and by extension partnershipis something 'done to' rather than 'done with' students" (MercerMapstone et al., 2017, p. 15). Our partnership embraces a value-added mindset, in which we are equal participants in this endeavor.

In this article, we describe our process, highlight instructional benefits, and discuss the characteristics of our working relationship. While our results are limited due to the contextspecific nature of this work (see Healey \& Healey, 2018), we share our experiences of our partnership and its outcomes in order to highlight a way through which faculty and students can work together to improve instruction in higher education, especially in teacher education programs.

\section{CONTEXT}

This student-faculty partnership involved an education undergraduate student and a teacher education faculty member at Lesley University. The institution was founded in 1909 as an institution for training kindergarten teachers and continues to have a strong commitment to PreK-12 teacher preparation. Caroline, the student in our partnership and the second author, was a teaching assistant (TA) who had completed the introductory teacher education course in the semester prior to our collaboration. The course met once a week for two-and-a-half hours. Frank, the faculty member in the partnership and the first author, had taught this class numerous times. Given our focus on Frank's course instruction, we discussed, analyzed, and critiqued Frank's pedagogy as reflective practitioners. A reflective practitioner is someone who

examines, frames, and attempts to solve the dilemmas of classroom practice; is aware of and questions the assumptions and values he or she brings to teaching; 
is attentive to the institutional and cultural contexts in which he or she teaches. .

. (Zeichner \& Liston, 1996, p. 6)

\section{LEARNINGS}

To support our work, Caroline took weekly video of Frank's teaching, which we individually reviewed. We each crafted individual reflections highlighting key observations from our review, such as strengths, next steps, and further areas to explore, and met weekly to share our observations. We have organized our learning into process, teaching and learning, and relationship. Additionally, within these areas, we discuss our shared learnings and, at times, use individual first person narratives. This enables us to highlight our unique lived experiences within the partnership.

\section{Process}

\section{Shared Thoughts}

At the beginning of the partnership, we established our roles and responsibilities. Caroline's roles and responsibilities involved attending each class, recording Frank's teaching, occasionally co-teaching, watching and writing reflections on the weekly videos of Frank's teaching, attending weekly meetings with Frank to discuss his teaching, and taking notes during these meetings. These roles spanned the spheres of student engagement indicated by Healey, Flint, and Harrington (2014) and included learner, assessor, pedagogical consultant, and scholar. Similarly, Frank's roles and responsibilities included preparing and teaching each class, supporting Caroline's work as a TA, reviewing the weekly videos, writing reflections about his teaching, and discussing his pedagogy with Caroline during weekly meetings.

\section{Caroline's Thoughts}

As a freshman, I enrolled in an introductory education course taught by Frank. This course gave me the opportunity to learn about teaching theories, inequalities in education, and diverse educational systems. After completing this course, Frank asked if I would be his TA for the following fall semester. In addition to my position as a TA, Frank asked if I would participate in a partnership that aimed to improve his teaching pedagogy with the help of my perspective as an undergraduate student.

I was thrilled to be offered this opportunity to participate in a unique form of professional development. Additionally, we would engage in conversations that I found invaluable as I got to have one-on-one time with an expert in the field. Frank also discussed the possibility of writing a paper for publication on our partnership and shared experience. This factor played a significant role in my affirmative decision, as I had not had a similar opportunity presented to me before, and was extremely curious to engage in the world of academia through research. It is worth noting that I had thoroughly enjoyed being in Frank's class, and I related to his enthusiasm and dedication to the field. After I considered what this role of a TA and student-partner might mean for my present and future self, I committed and our partnership was formed.

Frank's Thoughts 
Prior to becoming a faculty member, I was an elementary school teacher. When I was a first and second grade teacher, my classroom teaching was routinely observed by administrators. This led to numerous stakeholders providing me feedback about my instruction. While these observations were intimidating at the time, they were valuable and useful to enhance my pedagogical practices.

In comparison, as a faculty member, I am observed infrequently by my peers or administrators. When these observations are scheduled, I am often left wondering if my practice during these observations reflects how I typically teach. Course evaluations function as the main source for teaching feedback. However, despite my evaluations being positive overall, student feedback often lacks adequate detail to inform specific changes to teaching practice. In addition, while faculty professional development reviews important topics such as LGBTQ+ inclusivity, I find these sessions focus minimally on classroom pedagogy.

I desired a form of professional development centered on my teaching and learning in the classroom. This desire to embellish my instruction prompted the partnership with Caroline, an exceptional student. She is passionate about education and seeks out learning opportunities. I thought Caroline's perspectives would be invaluable. Despite my commitment to make my pedagogy better, I was nervous going into this partnership. It is challenging being critical of one's own practice, especially when the intended audience (undergraduate students) is a part of the critical reflection process. While I was intimidated by this endeavor, I also believed that the process could positively impact my instruction, as well as my thinking about faculty professional development in higher education.

\section{Shared Thoughts}

The videos provided us with the data necessary to ground specific comments in evidence. The process for reviewing the weekly videos and reporting findings was unstructured. Rich conversations occurred over time, as these depended on the evolving relationship between us, and Caroline's comfort with analyzing Frank's practice.

\section{Teaching and Learning}

Caroline's Thoughts

My perspectives as a current student and a future educator evolved through observing Frank's instruction. As a student, I learned how to further engage in research and work with university faculty. Through discussions with Frank, I was more aware of the requirements and time commitments that university faculty have outside of their classrooms. As a result, I gained a deeper appreciation for the time that teachers commit to their classrooms, considering their outside obligations. Observing and interacting with Frank reinforced the idea that educators and faculty members are not all-knowing beings. Rather, they are experts who, like myself as a teacher candidate, possess doubts and insecurities about their pedagogic practices.

I appreciated that Frank expressed his position of vulnerability by letting an undergraduate student provide commentary and perspective on his practice. This partnership, inquiry, and professional development was not initiated because of a Lesley University mandate or requirement, but because Frank wanted to improve his practice in his own time. As a 
student, it is extremely encouraging to know that certain educators always want to improve themselves in order to become better teachers, and not just because they are required to engage in professional development.

More importantly, my perspective as an aspiring educator was influenced through working with an expert in the academic field, which I am passionate about. As a future educator, I further realize that one's pedagogy never stops changing, and each experience promotes learning. The importance of critical self-reflection within education was reinforced through my background research for our partnership, along with witnessing Frank engage in critical self-reflection firsthand. Early on in our meetings, Frank discussed that critical selfreflection is taught in undergraduate education programs as a way to improve instructional practices. However, he believes that faculty members seldom use self-reflection to critically examine their own pedagogy.

\section{Frank's Thoughts}

My perspectives about my practice changed. Viewing the weekly videos assisted with my critical reflections about my teaching. Specifically, I identified areas of strength as well as aspects to develop. Caroline's insight contributed to my thinking about my practice. While redundancy in knowledge between Caroline and me aided with confirming some findings, having diversity of knowledge during the reflection process assisted me with realizing new knowledge about instruction. For example, I noticed that I was responsive to students' posed questions without inhibiting the flow of the class. While Caroline recognized this too, she suggested that I pose the asked questions to the whole class before giving the student a response. In doing so, I could more effectively capitalize on students' expertise. While this change may seem minor, it subtly changed the dynamic of the class. Students are positioned as experts or individuals with valuable knowledge. They are not merely passive receivers of content, but rather active participants who possess information that can inform the class' learning. This example is one way that Caroline's insight helped me to improve my practice.

My critical reflection and Caroline's feedback contributed to substantial changes to my teaching. Some of these changes included providing students additional opportunities to discuss field placements in unstructured ways, and making additional explicit connections between theory and practice.

\section{Relationship}

The effectiveness of our student-faculty partnership relied primarily on the quality of our working relationship. We had to feel comfortable with one another. Often emotions are absent from student-faculty partnership literature (Felten, 2017); however, successful collaborations involve participants feeling comfortable with one another. For us, this is easy to discuss but was challenging to enact in an authentic manner. Uneasiness in partnerships is not only isolated to student partners. For example, Ntem and Cook-Sather discuss how faculty in partnerships with students are often "cautious about entering into conversations with their student partners regarding personal insecurities, worries, or moments of joy in the classroom" (2018, p. 82). These concerns can manifest in resistance. In order to minimize emotional 
challenges, we extensively discussed power dynamics and their influence on our partnership. In addition, we openly shared our uneasiness about the process. The discomfort centered on Frank having his practice critiqued by Caroline, and Caroline critically analyzing Frank's teaching. This process significantly changes the traditional power dynamic between a student and a faculty member. While this social hierarchy existed in our partnership, we minimized the power imbalance by respecting the process and openly sharing our discomfort. We have decided to share Caroline's lived experiences in this section because, arguably, the existing power dynamic for her, as a student working with a faculty member, was more challenging to overcome in order for this partnership to be successful. Here are Caroline's insights:

I was able to be truthful and comfortable within the partnership as a result of Frank's use of positive reinforcement, both through implementing my ideas for his practice and verbally encouraging my writing and opinions. Frank consistently used collective terminology for our partnership, such as "our study" and "we" instead of something along the lines of "my study." He also made it a point to talk about what I, as the student-partner, was hoping to get out of our shared experience. I wanted to know more about effective teaching practices, student-faculty communication, and the process of developing research. Frank's interest in, and positive reinforcement of, my opinions aided my ability to bring up topics of my own interest.

We noticed that establishing a productive working relationship took time. During our first meetings, the conversations mostly centered on our partnership work. However, as the semester progressed, we began learning more about one another and a common question that we started our meetings with was, "What have you been up to?" While this seems very basic, it captures the essence of our developing relationship. We discussed current political topics, our families, and educational matters. While often not related specifically to our partnership work, these conversations functioned to develop our professional working relationship, as Caroline discusses:

Honest and genuine conversation led me to be more comfortable and sincere in our professional relationship, especially when it came to voicing my recommendations and thoughts on Frank's practice. As time went on, I trusted his opinion and was inspired by his energy and dedication to the field of education. It felt great to have someone who respected my opinion and gave me valuable insight in return. Because I was able to know Frank on a more personal level, it helped me understand his thought process during the conducting and planning of class lessons. Therefore, the level of trust between faculty-partner and student-partner increases with the more time (short-term and long-term) that each member is willing to commit.

\section{RECOMMENDATIONS}

Teacher education faculty must find ways to advance their pedagogical practices. One such way is through student-faculty partnerships. These partnerships require minimal financial 
resources, which make them a viable option for faculty members seeking to improve their pedagogy. In our case, Lesley University does not pay undergraduate teaching assistances, so Caroline was not paid for her involvement in our partnership.

Collaboration in the reflection process is necessary in order to challenge assumptions, expand interpretations, and check for inconsistencies (Vanassche \& Kelchtermans, 2015). Given the demands placed on many faculty at institutions of higher education, it is often unrealistic for colleagues to consistently observe and review teaching. Student-faculty partnerships are another way for faculty to receive critical feedback about instruction.

This case study exemplifies how a teaching assistant, who is already assigned to a course, can partner with a faculty member to improve his or her course instruction. While challenges such as time constraints exist with these types of partnerships (see Curran, 2017), they can enhance learning for those who participate in them. For example, student partners can enhance their understanding of professional development and further their own classroom instruction in the future. We provide three recommendations for those engaging in these collaborations as well as those looking to conduct research on these partnerships.

Our first recommendation is to record faculty teaching. Video in our partnership served to support our findings about the course instruction and helped facilitate conversations about instruction. We also believe that, for partnerships existing over the course of multiple years, video could be used to better assess changes to the faculty partner's curriculum and instruction.

Our second recommendation is for faculty and students to establish roles at the onset of collaborations. Having well-defined roles facilitates partnership work, supports accountability, and may minimize faculty and student trepidations, anxiety, and vulnerability about their pedagogy. For instance, faculty who are having misgivings or feeling too vulnerable may become resistant to partnership work. According to Ntem and Cook-Sather, faculty resistances in pedagogical partnerships "include resistance to being openly vulnerable about their work with their student partners, resistance to trying new pedagogical strategies, and resistance to simply asking for their student partners' perspectives on classroom practice" (2018, p. 82-83). In addition, we advocate for those engaged in future student-faculty partnership research to describe processes, which consist of partnership roles, responsibilities, and power dynamics. Cook-Sather and Luz state, "The traditional divisions of knowledge and authority in relation to teaching and learning make it hard for [students and faculty] to change roles, responsibilities and sense of self" (2015, p. 1101). More reporting on partnership processes in the literature will better support development of successful student-faculty partnerships.

Our third and final recommendation is for faculty and students engaged in partnership to confront the power dynamics that exist between them. Thoughtful discussions must happen within these collaborations in order to reconcile power relations (Delphish et al., 2010; Hutchings, Bartholomew, \& Reilly, 2013). While each context is unique, these collaborations redefine traditional academic roles between faculty and students. We encourage partners to share their uneasiness with one another. Student-faculty partnerships will only be successful if participants feel truly comfortable sharing their thoughts and feelings. As we have already mentioned, partnership literature often ignores emotional elements of human collaborations 
(see Felten, 2017); however, student-faculty partnerships are emotional endeavors as much as academic endeavors. Participants need to recognize that it takes time to establish authentic and trusting working relationships. Through these partnerships, students and faculty can learn together, and faculty can enhance their instructional practices, which will thus benefit all current and future students.

\section{NOTE ON CONTRIBUTORS}

Frank Daniello is an Associate Professor of Elementary Education in the College of Liberal Arts and Sciences at Lesley University, Massachusetts, United States. Frank's research focuses on teachers' use of systemic functional linguistics (SFL) to inform writing pedagogy, schooluniversity partnerships, teacher professionalism, and school reform.

Caroline Acquaviva is an undergraduate student studying English and Secondary Education at Lesley University with a concentration in multicultural education. Caroline hopes to further research best practices for teachers serving in diverse classrooms and communities.

\section{REFERENCES}

Commission on the Future of Undergraduate Education. (2017). The future of undergraduate education: The future of America. Retrieved from https://www.amacad.org/cfue

Cook-Sather, A., \& Luz, A. (2015). Greater engagement in responsibility for learning: What happens when students cross the threshold of student-faculty partnership. Higher Education Research \& Development, 34(6), 1097-1109.

https://doi.org/10.1080/07294360.2014.911263

Curran, R. (2017). Student as partners - good for students, good for staff: A study on the impact of partnership working and how this translates to improved student-staff engagement. International Journal for Students as Partners, 1(2), 1-16. https://doi.org/10.15173/ijsap.v1i2.3089

Delphish, A., Holmes, A., Knight-McKenna, M., Mihans, R., Darby, A., King, K., \& Felten, P. (2010). Equalizing voices: Student-faculty partnership in course design. In C. Werder \& M. M. Otis (Eds.), Engaging student voices in the study of teaching and learning (p. 96114). Sterling, VA: Stylus Publishing.

Felten, P. (2017). Emotion and partnerships. International Journal for Students as Partners, 1(2), 1-5. https://doi.org/10.15173/ijsap.v1i2.3070

Goos, M., \& Salomons, A. (2017). Measuring teaching quality in higher education: Assessing selection bias in course evaluations. Research in Higher Education, 58(4), 341-364. https://doi.org/10.1007/s11162-016-9429-8

Healey, M., Flint, A., \& Harrington, K. (2014). Engagement through partnerships: Students as Partners in learning and teaching in higher education. York, UK: Higher Education Academy. 
Healey, M., \& Healey, R. L. (2018). "It depends": Exploring the context-dependent nature of Students as Partners practices and policies. International Journal for Students as Partners, 2(1), 1-10. https://doi.org/10.15173/ijsap.v2i1.3472

Hutchings, C., Bartholomew, N., \& Reilly, O. (2013). Differential student engagement: Lessons learned. In C. Nygaard, S. Brand, P. Bartholomew, \& L. Millard (Eds.), Student engagement: Identity, motivation and community (pp. 125-144). Faringdon, UK: Libri Publishing.

Loughran, J. J. (2006). Developing a pedagogy of teacher education: Understanding teaching and learning about teaching. New York, NY: Taylor and Francis.

Mercer-Mapstone, L., Dvorakova, L. S., Matthews, K., Abbot, S., Cheng, B., Felten, P., Knorr, K., Marquis, E., Shammas, R., \& Swaim, K. (2017). A systematic literature review of Students as Partners in higher education. International Journal of Students as Partners, 1(1), 1-23. https://doi.org/10.15173/ijsap.v1i1.3119

Ntem, A., \& Cook-Sather, A. (2018). Resistances and resiliencies in pedagogical partnership: Student partners' perspectives. International Journal for Students as Partners, 2(1), 8296. https://doi.org/10.15173/ijsap.v2i1.3372

Phuong, T. T., Cole, S. C., \& Zarestky, J. (2018). A systematic literature review of faculty development for teacher educators. Higher Education Research \& Development, 37(2), 373-389. https://doi.org/10.1080/07294360.2017.1351423

Spooren, P., Brockx, B., \& Mortelmans, D. (2013). On the validity of student evaluation of teaching: The state of the art. Review of Educational Research, 83(4), 598-642. https://doi.org/10.3102/0034654313496870

Swennen, A., Jones, K., \& Volman, M. (2010). Teacher educators: Their identities, sub-identities and implications for professional development. Professional Development in Education, 36(1-2), 131-148. https://doi.org/10.1080/19415250903457893

Vanassche, E., \& Kelchtermans, G. (2015). The state of the art in self-study of teacher education practices: A systematic literature review. Journal of Curriculum Studies, 47(4), 508-528. https://doi.org/10.1080/00220272.2014.995712

Zeichner, K. M., \& Liston, D. P. (1996). Reflective teaching: An introduction. Mahway, NJ: Lawrence Erlbaum Associates. 